\title{
Classical taxane versus the new generation, nab- paclitaxel chemotherapy in the treatment of breast
} \section{cancer}

\begin{abstract}
Breast cancer $(\mathrm{BC})$ remains the most invasive diagnosed cancers among female, affecting $25 \%$ of total number of cancers worldwide. Systematic chemotherapies still remain one of the effective treatments for $\mathrm{BC}$. One of the common and powerful chemotherapies that have been used in the past decade is taxane. Taxane are a class of anticancer compounds that are known to cause cell cycle arrest and apoptosis induction (cell death). They are used for the treatment of malignant tumors specifically BC along with other chemotherapies such as anthracycline. However, the neurotoxic effects that are associated with the use of taxane are still challenging. Recently, nanoparticle albumin bound taxane (nab-paclitaxel) was developed, resulting in lowering of the side effects that are associated with the use of taxane and enhancing its delivery to the targeted cancer cells. Nab-paclitaxel has been subjected to several clinical trials to evaluate its efficacy in the treatment of various types of cancers including $\mathrm{BC}$. The results indicated that nab-paclitaxel showed an improved efficacy and promising outcomes in the treatment of various forms of $\mathrm{BC}$. This review focuses on the comparison of classical taxane to the new generation, nab-paclitaxel chemotherapy, with emphasis on their comparative efficacy in metastatic BC (MBC) and triple negative metastatic $\mathrm{BC}$ (TNMBC) treatment, concluding that nab-paclitaxel has improved efficacy, safety data and with a more convenient administration confirming an optimal treatment option for patients in both cases. Future work is needed to optimize dosing schedules and combination regimens of nab-paclitaxel, which could broaden the clinical utility of this agent.
\end{abstract}

Keywords: taxane, nab-paclitaxel, breast cancer, metastatic breast cancer, triple negative metastatic breast cancer
Volume 4 Issue 3 - 2017

\author{
Ghada MA Ajabnoor ${ }^{1,2}$ \\ 'Department Clinical Biochemistry, King Abdulaziz University \\ (KAU), Saudi Arabia \\ ${ }^{2}$ King Abdulaziz University (KAU), Saudi Arabia
}

Correspondence: Ghada Ajabnoor MA, Clinical Biochemistry Department, King Abdulaziz University, Saudi Arabia, Email ga_clinbio@yahoo.com

Received: May 07, 2017 | Published: May 30, 2017
Abbreviations: $\mathrm{BC}$, breast cancer; $\mathrm{MBC}$, metastatic breast cancer; $\mathrm{TNMBC}$, triple negative metastatic breast cancer

\section{Introduction}

$\mathrm{BC}$ is considered the most frequently diagnosed invasive malignancy-affecting females in both the developed and developingcountries. ${ }^{1-3}$ The prevalence of $\mathrm{BC}$ worldwide accounted for about $25 \%$ of total cancer cases diagnosed (1.68million), and is responsible for $15 \%$ of cancer deaths $(520,000)$ throughout the globe. 4,5 In the United States, recent epidemiological study estimated that 23,000 new cases of invasive $\mathrm{BC}$ are diagnosed annually resulting in almost 40,000 deaths. ${ }^{6}$ Unfortunately, it is believed that metastatic BC actual prevalence is likely to be higher than the estimates, since many women live with the tumor for many years before being diagnosed. Localized BC tumors have high potential of being cured with various established systemic therapies. ${ }^{8}$ In the past 30 years, BC systemic therapies have evolved from using anthracycline as chemotherapeutic agents during the 1980s to the use of taxane chemotherapy in the 1990 s, and more recently the biological therapies such as perception in 2000s. ${ }^{9,10}$ Taxane were used in combination with anthracycline and other alkylating agents in order to improve the overall survival (OS) rate, and disease free survival (DFS) among metastatic BC (MBC) patients. ${ }^{10,11}$ Therefore, taxane chemotherapy still remains an effective treatment for $\mathrm{BC}$ and is considered as the first line of therapy used for the treatment of $\mathrm{MBC}$ with success rate ranging from $25 \%$ to $69 \%{ }^{12,13}$
There are two main types of taxane: paclitaxel and docetaxel- second generation. ${ }^{14}$ The US Food and Drug Administration (FDA) was the first to approve paclitaxel for treating ovarian cancer in 1992 and subsequently for the treatment of MBC in $1994 .{ }^{15}$ In addition, taxane chemotherapy has been included in the management of early stage $\mathrm{BC}$ and issued routinely in combination with trastuzumab (Herceptin ${ }^{\circledR}$ ) and anthracycline. ${ }^{11,13,14}$ However, paclitaxel resulted in the induction of a high cytotoxicity in $\mathrm{BC}$ patients and especially among the elderly ones. ${ }^{13}$ The major side effects resulting from its use in $\mathrm{BC}$ patients include myelosuppression and neuropathy. ${ }^{13}$ Paclitaxel induce neuropathy primarily by injuring the dorsal root ganglia (DRG) neurons leading to a sequence of Neuropathological alterations in the DRG, dorsal horn of the spinal cord and peripheral nerve. ${ }^{16}$ When comparing the levels of peripheral neuropathy toxicities between paclitaxel and docetaxel in rats, paclitaxel showed more severe side effects in nerve fibers. ${ }^{17}$ However, the incidence of neutropenia and peripheral neuropathy was found to be dose dependent, and the association of neuropathy with paclitaxel was mainly sensory. ${ }^{18}$ Toxic effects were evident between 24-72h following the administration of single doses above $250 \mathrm{mg} / \mathrm{m}^{2}$, or following the intake of several doses between $135-200 \mathrm{mg} / \mathrm{m}^{2} .{ }^{18}$ The clinical manifestation of neuropathy included burning or tingling sensation in the glove and stocking areas, and can progress to motor weakness when drug administration is continued..$^{19}$ According to previous clinical studies and research, there are a number of clinical scales available for the assessment of taxane induced peripheral neuropathy. ${ }^{20}$ These measures are combination 
of objective and subjective metrics that are important to grade the severity of peripheral neuropathy. ${ }^{21}$ The most commonly used scale rating system assessed by the World Health organization (WHO), US National Cancer Institute Common Toxicity Criteria (NCI-CTC) and Eastern Cooperative Oncology Group (ECOG) scales are shown in Table $1 . .^{20-24}$

Table I The NCI CTC grading system for peripheral neuropathy

\begin{tabular}{ll}
\hline Grade No & Symptoms \\
\hline Grade I & Asymptomatic-clinical or diagnostic observations only \\
Grade II & Moderate symptoms- limiting activates of daily basis \\
Grade III & $\begin{array}{l}\text { Sever symptoms limiting self-care and activates of daily basis } \\
\text { Grade IV }\end{array}$ \\
$\begin{array}{l}\text { Life-treating consequences- require urgent intervention } \\
\text { indicated }\end{array}$ \\
GradeV & Death
\end{tabular}

Recently, a new generation of taxane based drugs have been developed and are known as nanoparticle albumin bound taxane (nab-paclitaxel). ${ }^{25,26}$ This modification was reported to exhibit less side effects than that normally produced from the use of taxane, and shows enhanced drug delivery into the targeted cancerous cells..$^{25,27,28}$ Nab-paclitaxel has been subjected to several phases of clinical trials. The results of those trials showed an improved efficacy and promising outcomes in patients with $\mathrm{BC} .{ }^{26}$ This review focuses on the comparison of classical taxane to the new generation, nab-paclitaxel chemotherapy, with emphasis on their comparative efficacy in metastatic breast cancer (MBC) and triple negative metastatic breast cancer (TNMBC) treatment.

\section{Classical taxane vs nanoparticle albumin- bound taxane ( $\mathrm{Nab}$-paclitaxel)}

\section{Chemical characteristics}

Taxane are a class of microtubule inhibitors that are natural products extracted from the bark of the Pacific Yew Taxus brevifolia tree. ${ }^{29}$ Two types of solvent based taxane have been developed, namely paclitaxel (Taxol), doxetaxel (Texture). Because of the hydrophobic nature of paclitaxel, it requires being administered in a solution containing alcohol and ChromophoreÒ EL 1:1 (polyoxyethylated castor oil) to enhance its delivery. ${ }^{30}$ Docetaxel on the other hand, is a second generation of taxane, which is taken intravenously. ${ }^{31}$ The established new generation of taxane is the nanoparticle albuminbound paclitaxel (Abraxane; nab ${ }^{\circledR}-$ Paclitaxel- Celgene Corporation, Summit, New Jersey, USA). ${ }^{32,33}$ In nanotechnology the size of particle ranges usually between 1 and 1000nanometers, hence are named nanoparticles. ${ }^{34}$ Thus, the high surface to volume ratio of these nanoparticles enhances the interaction with other molecules and allows flexibility in augmenting drug transport across challenging biological barriers including blood- brain and blood-tumor barriers. ${ }^{34}$ Furthermore, because of the hydrophobic nature of taxane such as paclitaxel, its solubility in aqueous media can be enhanced by enveloping it in albumin nanoparticles creating nab-paclitaxel,${ }^{34}$ which is a novel solvent free drug in colloidal suspension of 130nanometer particles with human serum albumin (3\%-4\%). This makes it easy to infuse in higher doses than the standard dose of paclitaxel, and with higher response and lower toxicities, as well as less infusion time (30minutes) in patients with advanced $\mathrm{MBC}$ and non small cell lung cancer (NSCLC). ${ }^{30-35}$

\section{Molecular mechanisms}

Both paclitaxel and doxetaxel share the same mechanism of action with different pharmacokinetics and side effects. ${ }^{36}$ However, doxetaxel is poorly tolerated clinically and less effective than paclitaxel and is, therefore, not frequently used..$^{31,37}$ The exact cellular molecular mechanism of action of paclitaxel relies in its ability to bind to b-tub line (the taxane target site) in the mitotic spindle. ${ }^{38}$ Thus, it stabilizes microtubules by inhibiting their depolymerization and interfering with their kinetochore attachment. ${ }^{39}$ The net result is to change the tension through the kinetochore in mitosis, thus disrupting mitosis and casing checkpoint arrest then inducing programmed cell death "apoptosis" through the mitochondrial pathway (Figure 1). ${ }^{39-41}$ However, drug dose and duration of usage play a critical role in the induction of cell death. ${ }^{42}$

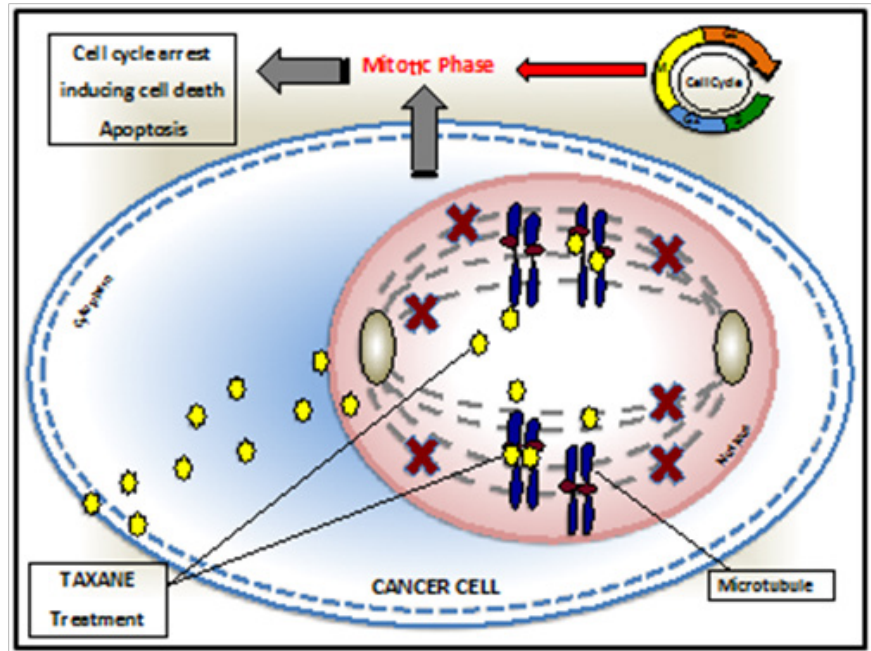

Figure I Cellular mechanism of taxane treatment on cancer cell.

On the other hand, nab-paclitaxel molecular mechanism is dependent on increased transport of paclitaxel to the tumor by albumin specifically binding to gp60 and facilitating caveolinmediated transcytosis to enhance delivery across the blood vessels endothelial cells, thus transporting paclitaxel into extra vascular space to the tumor cells, hence inducing apoptosis, and resulting in an advantageous pharmacokinetic (PK) profile (Figure 2). ${ }^{25,43}$ Indeed, several preclinical studies reported an approximately 10 -fold endothelial binding of nab-paclitaxel, and 4-fold higher levels of transocytosis through endothelial cells in contrast to the solvent based paclitaxel allowing for a dose dependent antitumor activity. ${ }^{43,44}$

\section{Dosage, bioavailability and therapeutic index in MBC}

According to clinical and oncology standards, taxane are usually used in combination with anthracycline regimen, or after anthracycline treatment in order to improve efficacy and reduce the relapse risk. ${ }^{47}$ A multicenter randomized phase III clinical trial was conducted on MBC patients where paclitaxel $\left(175 \mathrm{mg} / \mathrm{m}^{2}\right)$, or $\left(135 \mathrm{mg} / \mathrm{m}^{2}\right)$ was administrated for a period of 3 weeks $(\mathrm{q} 3 \mathrm{w}){ }^{48-50}$ The results of this study indicated that higher doses of paclitaxel produced a superior overall response rate (ORR) as compared to using lower doses, and longer overall survival (OS) with a median time of tumor progression (TTP). ${ }^{48-50}$ Two similar previous studies were conducted on BC patients where four cycles of doxorubicin and Cyclophosphamide were initially administrated every 3 weeks, followed by the administration of four cycles of paclitaxel every 3 weeks..$^{51,52}$ The obtained results 
revealed an endorsement for the use of paclitaxel in treatment with positive axillary lymph node, and thus established new standards for BC care. ${ }^{51,52}$ Furthermore, in another study, the efficacy of the administration of deoctaxel with doxorubicin and Cyclophosphamide in the management of positive node $\mathrm{BC}$ patients was investigated, and the results showed a higher efficacy of the above combination compared to fluorouracil, doxorubicin and Cyclophosphamide. ${ }^{32}$

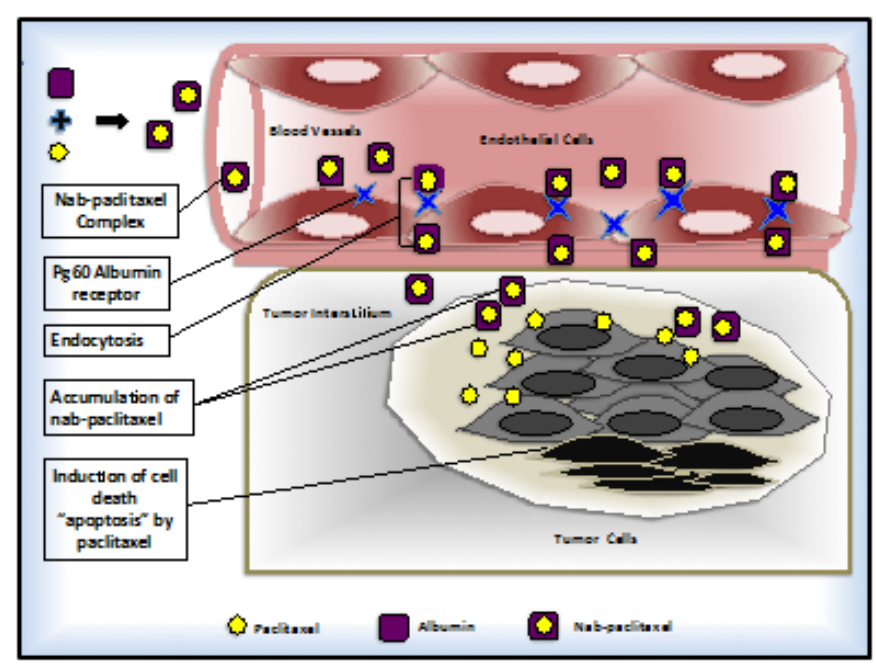

Figure 2 Cellular mechanism of nab-paclitaxel on cancer cell.

Similarly, a number of preclinical studies were conducted on nab-paclitaxel, and reported that it accomplished higher intracellular concentration compared to standard paclitaxel with improved bioavailability, efficacy and therapeutic index on different animal's models. ${ }^{43}$ Subsequently, nab-paclitaxel was licensed in Europe and approved by the FDA in 2005 for MBC patients who failed all first line treatments including anthracycline-containing therapy. ${ }^{33}$ More recently, a phase III clinical trial on MBC patients was conducted where $260 \mathrm{mg} / \mathrm{m}^{2}$ nap-paclitaxel was applied every week compared to $175 \mathrm{mg} / \mathrm{m}^{2}$ of paclitaxel every 3 week, and was found to show significant improvement in outcomes including overall response rate (ORR), time of tumor progression (TTP) and progression free survival (PFS). ${ }^{11,53}$ According to this data, nab-paclitaxel dose of $260 \mathrm{mg} / \mathrm{m}^{2}$ every 3 week has obtained an approval for use in MBC in more than 40countries. ${ }^{54,55}$ Furthermore, nab-paclitaxel has been shown to reduce drug exposure to healthy tissue. ${ }^{43}$ In addition, the intravenous infusion was reported to be controlled and safer compared with paclitaxel due to the use of standard plastic intravenous bags which are possible to reconstitute in smaller volume of normal saline. ${ }^{56}$

\section{Clinical challenges in MBC- comparing taxane to nab- paclitaxel:}

The major challenge that faces clinicians when treating $\mathrm{BC}$ patients is the severe toxic side effects that are produced by taxane, and especially among the elderly patients. ${ }^{13}$ The major side effects include: myelosuppression, neutropenia and neuropathy. ${ }^{13}$ A previous clinical trial investigated the efficacy of weekly administered paclitaxel compared to administering paclitaxel every 3 weeks in 500BC patients. ${ }^{31}$ Results showed that patients on paclitaxel weekly administration were susceptible to grad II, III and IV neuropathy (27\%) more than patients with paclitaxel every 3 weeks administration $(20 \%){ }^{31}$ However, regarding the efficacy they found that using adjuvant chemotherapy with doxorubicin and Cyclophosphamide, followed by weekly paclitaxel has improved disease-free and OS in females with BC. ${ }^{31}$ Therefore, the number of paclitaxel infusion times and dose is strongly related to the severity and incidence of peripheral neuropathy. ${ }^{18,19}$ Therefore, premedication requirement for patients receiving paclitaxel or doxetaxel is necessary, in order to reduce the neurotoxic side effects caused by these agents. ${ }^{18}$ However, there is variation in the guideline recommendations for paclitaxel and doxetaxel. ${ }^{57}$ Thus, patients receiving paclitaxel require intravenous antagonists of histamine $\mathrm{H} 1$ and $\mathrm{H} 2$ plus oral corticosteroids $24 \mathrm{~h}$ prior to drug infusion, in contrast to patients receiving doxetaxel who are recommended to receive premedication regimen consisting of 3 days of oral dexamethasone ( $8 \mathrm{mg}$ twice daily). ${ }^{57}$ Moreover, corticosteroid medication is important and needed to prevent hypersensitivity reaction, and to delay the onset and reduce the severity of fluid retention, skin and nail changes. ${ }^{57}$

In contrast, the lack of solvent in the nab-paclitaxel formulation has lead to reduction of the acute toxicity reactions, and has assisted in escaping the use of corticosteroid and antihistamine premedication. ${ }^{58}$ Furthermore, this new drug formula was shown to increase paclitaxel delivery and activity to tumors 4-5 folds because it combines with albumin receptors through the endothelial cells. ${ }^{59,60} \mathrm{~A}$ study demonstrated the use of nab-paclitaxel in combination with lapatinib treatment for MBC patients $(\mathrm{n}=55) \cdot{ }^{26}$ In this study, the first ten patients were treated initially with $125 \mathrm{mg} / \mathrm{m}^{2}$ nab-paclitaxel every 3 weeks for four cycles in combination with laptinib $1.25 \mathrm{mg}$ orally once a day for 4weeks. ${ }^{26}$ However, the first five patients developed grade III toxicity (neutropenia), therefore the doses for both drugs were decreased. ${ }^{26}$ Thus all following patients received $\left(100 \mathrm{mg} / \mathrm{m}^{2}\right)$ nab-paclitaxel every 3 week for three cycles, and $1 \mathrm{mg}$ laptinib orally once a day for 4 weeks. The RR was $53 \%$ and the PFS with TTP were $39.7 \%$ weeks. ${ }^{26}$ Untch et al. ${ }^{61}$ group conducted a phase III randomized trial, comparing the use of $150 \mathrm{mg} / \mathrm{m}^{2}$ nab-paclitaxel intravenous treatment for four 3 week cycles to standard paclitaxel of $80 \mathrm{mg} / \mathrm{m}^{2}$ for four 3week cycles on two groups of MBC $(\mathrm{n}=1230) .{ }^{61}$ After taxane treatment both groups were given intravenous epirubcin $90 \mathrm{mg} / \mathrm{m}^{2}$ plus Cyclophosphamide $600 \mathrm{mg} /$ $\mathrm{m}^{2}$ for four 3 week cycles. In addition patients with HER2 (human epidermal growth factor receptor 2) positive received subsequently herceptin (trastuzumab) therapy. The data from this trial revealed that complete pathological response was achieved in the nab-paclitaxel group (38\%) compared to the standard paclitaxel group (29\%). The incidence of grade III toxic effects; including anemia; was about $2 \%$ in nab-paclitaxel, whereas $1 \%$ anemia incidence was noted in paclitaxel group. In addition, peripheral neuropathy grade III-IV was noted in $10 \%$ of nab-paclitaxel group and $8 \%$ in paclitaxel group. ${ }^{61}$

Collectively, above data demonstrated that nab-paclitaxel shows better antitumor activity and efficacy with shorter infusion duration and higher concentration compared to paclitaxel that require pretreatment of patient and can cause drug resistance. ${ }^{62}$ Thus, nabpaclitaxel drug can safely be offered to many women with $\mathrm{MBC}$, with reasonable expectations of clinical benefit and without concern of significant toxicity.

\section{Taxane and nab-paclitaxel use in triple negative metastatic breast cancer (TNMBC)}

The TNMBC has become one of the aggressive clinical cancers with poor prognosis among $\mathrm{BC}$ patients, being found in $15 \%$ to $20 \%$ of all BCs. ${ }^{63-67}$ TNMBC is generally composed of heterogeneous group of cancers with high rate of proliferation and poorly differentiated cells. ${ }^{68}$ Patients with TNBC present early disease recurrence, and reduced survival rate compared with other $\mathrm{BCs} .{ }^{68}$ This type of $\mathrm{BC}$ is 
characterized by the lack of both estrogen and progesterone receptors (ER and PR), and lack of human epidermal growth factor 2 (Her2), ${ }^{66}$ which limits the treatment options for females affected with it. ${ }^{66}$ The standard treatment for TNMBC is chemotherapy, with taxane regimen being one of the effective therapies used with improved outcomes. ${ }^{69}$ In general, the use of single agent chemotherapy is preferred in most cases of MBC. ${ }^{48}$ However, the National Comprehensive Cancer Network guidelines suggested the use of combination treatments in TNMBC.$^{70,71}$ Platinum agents in combination with other chemotherapy has established an antitumor activity in TNMBC..$^{72,73}$ A small randomized phase II study for first line therapy was carried out on 53 female with TNMBC. Patients were given different combinations of chemotherapy: doxetaxel with capecitabine compared with doxetaxel with cisplatin. Results of the study indicated that the use of platinum agent plus taxane regimen produced grater efficacy than capecitabine regimen, with improved ORR, OS and progression-free survival (PFS). ${ }^{74}$ However, there is a limitation in the availability of optimal care of regimen for TNMBC patients. ${ }^{68}$ Hence, the lack of established molecular targets therapy and poor prognosis are still major obstacles for TNMBC patients and oncologists. ${ }^{75}$

Nevertheless, treating TNMBC patients with nab-paclitaxel was convenient, and hence proposed because of the therapeutic index of this drug that was investigated in a phase III trial..$^{53}$ Moreover addition of nab-paclitaxel to platinum based regimen in patients with TNMBC showed to be effective. ${ }^{75}$ The phase II trial used nab-paclitaxel $\left(100 \mathrm{mg} / \mathrm{m}^{2}\right)$ every $3-4$ weeks in combination with carboplatin plus bevacizumab observed an effective antitumor activity in TNMBC patients producing $85 \%$ ORR ${ }^{75}$ Moreover, further retrospective analysis of data in phase II trials recommended the use of nabpaclitaxel in combination of therapy for patients with TNMBC who were treated with taxane previously. ${ }^{62,74,76}$ In addition, a case study reported that a 48year female with TNMBC who was treated with first line adjuvant chemotherapy, experienced an excellent response to taxane treatment. ${ }^{58}$ However, due to her apparent hypersensitivity reactions towards paclitaxel her treatment was terminated. ${ }^{58}$ The patient was then recommended to start with nab-paclitaxel as a second line therapy, and showed a high response with limited toxicities. ${ }^{58}$ Therefore, nab-paclitaxel may be particularly beneficial for patients with TNMBC. Continuing research to evaluate the different dosing schedules and combination regimens of nab-paclitaxel could broaden the clinical utility of this agent in the future. ${ }^{77}$

\section{Conclusion}

In this era of improved outcomes with molecularly targeted $\mathrm{BC}$ therapy, through better understanding of tumor biology, it has become possible to devise methods to improve drug delivery to a complex tumor microenvironment as in the case of $\mathrm{BC}$. The development of nab-paclitaxel and its success in the treatment of $\mathrm{MBC}$ is a prime example of the interface between concepts of nanotechnology and the ingenious principles of drug development to target $\mathrm{BC}$. In addition, nab-paclitaxel showed to be an effective treatment for TNMBC patients, and is recommended as second line chemotherapy. Though, several questions on this novel formulation are still unresolved such as the optimal dose and treatment schedule, which risk population subgroups in the adjuvant and neoadjuvant settings of $\mathrm{BC}$, will benefit most, and whether it is possible to reverse prior resistance to taxane with nab-paclitaxel-paclitaxel. Therefore, it will be crucial and necessary to investigate these issues in the future findings. In conclusion, present data indicate that nab-paclitaxel has improved efficacy, safety data and with more convenient administration confirming an optimal treatment option for patients with MBC.

\section{Acknowledgements}

None.

\section{Conflict of interest}

The author declares no conflict of interest.

\section{References}

1. Hansen J. Increased Breast Cancer Risk among Women Who Work Predominantly at Night. Epidemiology. 2001;12(1):74-77.

2. El Bcheraoui $\mathrm{C}$, Basulaiman $\mathrm{M}$, Wilson $\mathrm{S}$, et al. Breast cancer screening in Saudi Arabia: free but almost no takers. PLoS One. 2015;10(3):e0119051.

3. Krieger N, Bassett MT, Gomez SL. Breast and cervical cancer in 187 countries between 1980 and 2010. Lancet. 2012;379(9824):1391-1392.

4. Jemal A, Center MM, DeSantis C, et al. Global patterns of cancer incidence and mortality rates and trends. Cancer Epidemiol Biomarkers Prev. 2010;19(8):1893-1907.

5. Torre LA, Bray F, Siegel RL, et al. Global cancer statistics, 2012. CA Cancer J Clin. 2015;65(2):87-108.

6. Siegel RL, Miller KD, Jemal A. Cancer statistics, 2015. CA Cancer J Clin. 2015;65(1):5-29.

7. Stebbing J, Glassman R. Breast cancer (metastatic). Clin Evid. 2004;(11):2266-2299.

8. Anampa J, Makower D, Sparano JA. Progress in adjuvant chemotherapy for breast cancer: an overview. BMC Medicine. 2015;13(1):1-13.

9. Nabholtz JM, Reese DM, Lindsay MA, et al. Combination chemotherapy for metastatic breast cancer. Expert Rev Anticancer Ther. 2002;2(2):169180 .

10. Coley HM. Mechanisms and strategies to overcome chemotherapy resistance in metastatic breast cancer. Cancer Treat Rev. 2008;34(4):378390.

11. von Minckwitz G, Martin M, Wilson G, et al. Optimizing taxane use in MBC in the emerging era of targeted chemotherapy. Crit Rev Oncol Hematol. 2013;85(3):315-331.

12. Ajabnoor GM, Crook T, Coley HM. Paclitaxel resistance is associated with switch from apoptotic to autophagic cell death in MCF-7 breast cancer cells. Cell Death Dis. 2012;3:e260.

13. Biganzoli L, Aapro M, Loibl S, et al. Taxanes in the treatment of breast cancer: Have we better defined their role in older patients? A position paper from a SIOG Task Force. Cancer Treat Rev. 2016;43:19-26.

14. Bachegowda LS, Makower DF, Sparano JA. Taxanes: impact on breast cancer therapy. Anticancer Drugs. 2014;25(5):512-521.

15. Gueritte F. General and recent aspects of the chemistry and structureactivity relationships of taxoids. Curr Pharm Des. 2001;7(13):12291249.

16. Peters CM, Jimenez-Andrade JM, Kuskowski MA, et al. An evolving cellular pathology occurs in dorsal root ganglia, peripheral nerve and spinal cord following intravenous administration of paclitaxel in the rat. Brain Res. 2007;1168:46-59.

17. Persohn E, Canta A, Schoepfer S, et al. Morphological and morphometric analysis of paclitaxel and docetaxel-induced peripheral neuropathy in rats. Eur J Cancer. 2005;41(10):1460-1466.

18. Guastalla JP, Dieras V. The taxane: toxicity and quality of life considerations in advanced ovarian cancer. Br J Cancer. 2003;89 Suppl 3:S16-S22.

19. Pazdur R, Kudelka AP, Kavanagh JJ, et al. The taxoids: paclitaxel (Taxol) and doxetaxel (Texture). Cancer Treat Rev. 1993;19(4):351-386. 
20. Carlson K, Ocean AJ. Peripheral neuropathy with microtubule-targeting agents: occurrence and management approach. Clinical breast cancer. 2011;11(2):73-81.

21. Common Terminology Criteria for Adverse Events (CTCAE). 2010;4(3):1-196.

22. Miller AB, Hoogstraten B, Staquet M, et al. Reporting results of cancer treatment. Cancer. 1981;47(1):207-214.

23. Oken MM, Creech RH, Tormey DC, et al. Toxicity and response criteria of the Eastern Cooperative Oncology Group. Am J Clin Oncol. 1982;5(6):649-655.

24. Postma TJ, Heimans JJ. Grading of chemotherapy-induced peripheral neuropathy. Ann Oncol. 2000;11(5):509-513.

25. Margolis J, McDonald J, Heuser R, et al. Systemic nanoparticle paclitaxel (nab-paclitaxel) for in-stent restenosis I (SNAPIST-I):a first-in-human safety and dose-finding study. Clin Cardiol. 2007;30(4):165-170.

26. Yardley DA, Raefsky E, Castillo R, et al. Results of a multicenter pilo study of weekly nab paclitaxel, carboplatin with bevacizumab and trastuzumab as neoadjuvant therapy in HER2 + locally advanced breast cancer with SPARC correlatives. Orlando, FL: Presented at: American Society for Clinical Oncology Annual Meeting. 2009

27. Yardley DA. nab-Paclitaxel mechanisms of action and delivery. $J$ Control Releas. 2013;170(3):365-372.

28. Roy V, LaPlant BR, Gross GG, et al. Phase II trial of weekly nab (nanoparticle albumin-bound)-paclitaxel (nab-paclitaxel) (Abraxane) in combination with gemcitabine in patients with metastatic breast cancer (N0531). Ann Oncol. 2009;20(3):449-453.

29. Schiff PB, Horwitz SB. Taxol stabilizes microtubules in mouse fibroblast cells. Proc Natl Acad Sci U S A. 1980;77(3):1561-1565.

30. Roy V, Perez EA. New therapies in the treatment of breast cancer. Semin Oncol. 2006;33(3 Suppl 9):S3-S8.

31. Martin M, Pienkowski T, Mackey J, et al. Adjuvant doxetaxel for nodepositive breast cancer. N Engl J Med. 2005;352(22):2302-2313.

32. Arpino G, Marmé F, Cortés J, et al. Tailoring the dosing schedule of nabpaclitaxel in metastatic breast cancer according to patient and disease characteristics: Recommendations from a panel of experts. Oncology Hematology. 2016;99:81-90

33. Abraxane summary of product characteristics. EMA. 2008.

34. Desai N. Challenges in development of nanoparticle-based therapeutics. AAPS J. 2012;14(2):282-295.

35. Cortes J, Saura C. Nanoparticle albumin-bound (nab ${ }^{\mathrm{TM}}$ )-paclitaxel: improving efficacy and tolerability by targeted drug delivery in metastatic breast cancer. European Journal of Cancer Supplements. 2010;8(1):1-10.

36. Gligorov J, Lotz JP. Preclinical pharmacology of the taxanes: implications of the differences. Oncologist. 2004;9 Suppl 2:3-8.

37. Mackey JR, Tonkin KS, Koski SL, et al. Final results of a phase II clinical trial of weekly docetaxel in combination with capecitabine in anthracycline-pretreated metastatic breast cancer. Clin Breast Cancer. 2004;5(4):287-292.

38. McGrogan BT, Gilmartin B, Carney DN, et al. Taxanes, microtubules and chemoresistant breast cancer. Biochim Biophys Acta. 2008;1785(2):96132

39. Kelling J, Sullivan K, Wilson L, et al. Suppression of centromere dynamics by Taxol in living osteosarcoma cells. Cancer Res. 2003;63(11):2794-2801.

40. Jordan MA, Wilson L. Microtubules as a target for anticancer drugs. Nat Rev Cancer. 2004;4(4):253-265.
41. Kienitz A, Vogel C, Morales I, et al. Partial downregulation of MAD1 causes spindle checkpoint inactivation and Aneuploidy, but does not confer resistance towards Taxol. Oncogene. 2005;24(26):4301-4310.

42. Murray S, Briasoulis E, Linardou H, et al. Taxane resistance in breast cancer: mechanisms, predictive biomarkers and circumvention strategies. Cancer Treat Rev. 2012;38(7):890-903.

43. Desai N, Trieu V, Yao Z, et al. Increased antitumor activity, intratumor paclitaxel concentrations, and endothelial cell transport of cremophorfree, albumin-bound paclitaxel, ABI-007, compared with cremophorbased paclitaxel. Clin Cancer Res. 2006;12(4):1317-1324

44. Gardner ER, Dahut WL, Scripture CD, et al. Randomized crossover pharmacokinetic study of solvent-based paclitaxel and nab-paclitaxel. Clin Cancer Res. 2008;14(13):4200-4205.

45. Vignesh Narayanan CDW. Nanoparticle albumin-bound (nab)-paclitaxel for the treatment of pancreas ductal adenocarcinoma. Gastrointestinal Cancer. 2015;5:11-19.

46. Al-Batran SE, Geissler M, Seufferlein T, et al. Nab-paclitaxel for metastatic pancreatic cancer: clinical outcomes and potential mechanisms of action. Oncol Res Treat. 2014;37(3):128-134.

47. Sparano JA, Wang M, Martino S, et al. Weekly Paclitaxel in the Adjuvant Treatment of Breast Cancer. N Engl J Med. 2008;358(16):1663-1671.

48. Sachdev JC, Jahanzeb M. Use of Cytotoxic Chemotherapy in Metastatic Breast Cancer: Putting Taxane in Perspective. Clin Breast Cancer. 2016;16(2):73-81.

49. Cortazar P, Justice R, Johnson J, et al. US Food and Drug Administration approval overview in metastatic breast cancer. $J$ Clin Oncol. 2012;30(14):1705-1711.

50. Nabholtz JM, Gelmon K, Bontenbal M, et al. Multicenter, randomized comparative study of two doses of paclitaxel in patients with metastatic breast cancer. J Clin Oncol. 1996;14(6):1858-1867.

51. Mamounas EP, Bryant J, Lembersky B, et al. Paclitaxel after doxorubicin plus Cyclophosphamide as adjuvant chemotherapy for node-positive breast cancer: results from NSABP B-28. J Clin Oncol. 2005;23(16):3686-3696.

52. Henderson IC, Berry DA, Demetri GD, et al. Improved outcomes from adding sequential Paclitaxel but not from escalating Doxorubicin dose in an adjuvant chemotherapy regimen for patients with node-positive primary breast cancer. J Clin Oncol. 2003;21(6):976-983.

53. Gradishar WJ, Krasnojon D, Cheporov S, et al. Phase II Trial of NabPaclitaxel Compared With Docetaxel as First-Line Chemotherapy in Patients With Metastatic Breast Cancer: Final Analysis of Overall Survival. Clin Breast Cancer. 2012;12(5):313-321.

54. Socinski MA, Bondarenko I, Karaseva NA, et al. Weekly nab-paclitaxe in combination with carboplatin versus solvent-based paclitaxe plus carboplatin as first-line therapy in patients with advanced nonsmall-cell lung cancer: final results of a phase III trial. J Clin Oncol. 2012;30(17):2055-2062.

55. Socinski MA, Manikhas GM, Stroyakovsky DL, et al. A dose finding study of weekly and every-3-week nab-Paclitaxel followed by carboplatin as first-line therapy in patients with advanced non-small cell lung cancer. J Thorac Oncol. 2010;5(6):852-861.

56. Cucinotto I, Fiorillo L, Gualtieri S, et al. Nanoparticle albumin bound Paclitaxel in the treatment of human cancer: nanodelivery reaches prime-time? J Drug Deliv. 2013;2013:905091.

57. Michaud LB, Valero V, Hortobagyi G. Risks and benefits of taxane in breast and ovarian cancer. J Drug Deliv. 2000;23(5):401-428.

58. Arpino G, De Placido S, De Angelis C. Nab-paclitaxel for the management of triple-negative metastatic breast cancer: a case study. Anticancer Drugs. 2015;26(1):117-122. 
59. Authier N, Gillet JP, Fialip J, et al. Description of a short-term Taxolinduced nociceptive neuropathy in rats. Brain Res. 2000;887(2):239-249.

60. Ibrahim NK, Desai N, Legha S, et al. Phase I and pharmacokinetic study of ABI-007, a Cremophor-free, protein-stabilized, nanoparticle formulation of paclitaxel. Clin Cancer Res. 2002;8(5):1038-1044

61. Untch M, Jackisch C, Schneeweiss A, et al. Nab-paclitaxel versus solvent-based paclitaxel in neoadjuvant chemotherapy for early breast cancer (GeparSepto-GBG 69):a randomised, phase 3 trial. The Lancet Oncology. 2016;17(3):345-356.

62. Blum JL, Savin MA, Edelman G, et al. Phase II study of weekly albuminbound paclitaxel for patients with metastatic breast cancer heavily pretreated with taxane. Clinical Breast Cancer. 2007;7(11):850-856.

63. Liedtke C, Mazouni C, Hess KR, et al. Response to neoadjuvant therapy and long-term survival in patients with triple-negative breast cancer. $J$ Clin Oncol. 2008;26(8):1275-1281.

64. Hudis CA, Gianni L. Triple-negative breast cancer: an unmet medical need. Oncologist. 2011;16 Suppl 1:1-11.

65. Bauer KR, Brown M, Cress RD, et al. Descriptive analysis of estrogen receptor (ER)-negative, progesterone receptor (PR)-negative, and HER2-negative invasive breast cancer, the so-called triple-negative phenotype: a population-based study from the California cancer Registry. Cancer. 2007;109(9):1721-1728.

66. Dent R, Trudeau M, Pritchard KI, et al. Triple-negative breast cancer: clinical features and patterns of recurrence. Clin Cancer Res. 2007;13(15 Pt 1):4429-4434.

67. Shastry M, Yardley DA. Updates in the treatment of basal/triple-negative breast cancer. Curr Opin Obstet Gynecol. 2013;25(1):40-48.

68. Yardley DA, Brufsky A, Coleman RE, et al. Phase II/III weekly nabpaclitaxel plus gemcitabine or carboplatin versus gemcitabine/carboplatin as first-line treatment of patients with metastatic triple-negative breast cancer (the tnAcity study): study protocol for a randomized controlled trial. Trials. 2015;16(1):1-10.
69. Hudis CA, Gianni L. Triple-negative breast cancer: an unmet medical need. Oncologist. 2011;16(Suppl 1):1-11.

70. Elizabeth H Wood. National Comprehensive Cancer Network. J Med Libr Assoc. 2004;92(3):382-383.

71. O'Shaughnessy J, Schwartzberg L, Danso MA, et al. Phase III study of iniparib plus gemcitabine and carboplatin versus gemcitabine and carboplatin in patients with metastatic triple-negative breast cancer. $J$ Clin Oncol. 2014;32(34):3840-3847.

72. O’Shaughnessy J, Schwartzberg L, Danso MA, et al. Phase III study of iniparib plus gemcitabine and carboplatin versus gemcitabine and carboplatin in patients with metastatic triple-negative breast cancer. $J$ Clin Oncol. 2014;32.

73. O'Shaughnessy J, Osborne C, Pippen JE, et al. Iniparib plus chemotherapy in metastatic triple-negative breast cancer. $N$ Engl J Med. 2011;364(3):205-214.

74. Fan Y, Xu BH, Yuan P, et al. Docetaxel-cisplatin might be superior to docetaxel-capecitabine in the first-line treatment of metastatic triplenegative breast cancer. Ann Oncol. 2013;24(5):1219-1225.

75. Hamilton E, Kimmick G, Hopkins J, et al. Nab-paclitaxel/bevacizumab/ carboplatin chemotherapy in first-line triple negative metastatic breast cancer. Clin Breast Cancer. 2013;13(6):416-420.

76. Lobo C, Lopes G, Baez O, et al. Final results of a phase II study of nab-paclitaxel, bevacizumab, and gemcitabine as first-line therapy for patients with HER2-negative metastatic breast cancer. Breast Cancer Res Treat. 2010;123(2):427-435.

77. Lohmann AE, Speers CH. Chia SK Evaluation of the clinical benefits of nanoparticle albumin-bound paclitaxel in women with metastatic breast cancer in British Columbia. Current Oncology. 2013;20(2):97-103. 